\title{
Development and characterization of novel microsatellite loci for Lusitanian toadfish, Halobatrachus didactylus
}

Carla Sousa-Santos, Paulo J Fonseca, Maria Clara P Amorim

The Lusitanian toadfish Halobatrachus didactylus is an eastern Atlantic polygynous species showing male paternal care. In this paper we describe 5 novel microsatellite loci obtained by 454 GS-FLX Titanium pyrosequencing of a microsatellite-enriched library. The number of alleles per polymorphic locus varied between 2 and 4 , and the observed heterozygosity ranged from 0.082 to 0.600 . No significant deviation from Hardy-Weinberg equilibrium was found and there was no evidence for linkage disequilibrium. These markers will be of great value for paternity studies and population genetics of this species. 
1 Carla Sousa-Santos ${ }^{1}$, Paulo J. Fonseca ${ }^{2} \&$ Maria Clara P. Amorim $^{1}$

$2 \quad{ }^{1}$ MARE - Marine and Environmental Sciences Centre, ISPA - Instituto Universitário, Rua Jardim 3 do Tabaco 34, 1149-041 Lisbon, Portugal

$4{ }^{2}$ Departamento de Biologia Animal and Centro de Biologia Ambiental, Faculdade de Ciências, 5 Universidade de Lisboa, Campo Grande, 1749-016 Lisbon, Portugal.

6 Corresponding author:

7 Carla Sousa Santos

8 ISPA, Rua Jardim do Tabaco 34, 1139-041 Lisboa, Portugal

9 E-mail: carla.santos@ispa.pt, Phone: +35121 8811700, Fax: +351218860954 
10

11

12

13

14

\section{Introduction}

Microsatellite markers (Tautz, 1989), i.e. highly variable DNA sequences of tandem repeats of 16 nucleotides with codominant inheritance, are widely used genetic markers in areas as diverse as phylogeography (e.g. Fauvelot \& Borsa, 2011), molecular ecology (e.g. Gardner et al., 2011) and parentage analysis (e.g. Jones et al., 2010). Despite their widespread use, the development of species-specific microsatellites can be challenging especially when a genomic library needs to be constructed and microsatellites must be developed de novo. This need arises when there are no microsatellite primers developed for closely related species.

In this work we describe novel microsatellite loci for Lusitanian toadfish Halobatrachus didactylus (Bloch \& Schneider, 1801) (Batrachoididae), obtained by 454 GS-FLX Titanium pyrosequencing that will be of great value for population genetics studies, namely to conduct paternity studies aiming to clarify the mating dynamics of this species.

The Lusitanian toadfish $H$. didactylus is a benthic fish species usually inhabiting shallow waters down to $50 \mathrm{~m}$ depth. It occurs in the eastern Atlantic, from Ghana to the Iberian Peninsula, and has its northernmost distribution limit at the Tagus estuary, in Portugal (Roux, 1986; Bauchot, 1987; Costa, Almeida \& Costa, 2003). In the breeding season males of H. didactylus defend nests under rocks, where they vocalize to attract females to mate with (Vasconcelos et al., 2012). Each female spawns a single batch of eggs annually, but males can guard eggs of several females (Modesto \& Canário, 2003; Amorim et al., 2010). In addition to nest-holder (type I) males there is a second male morphotype (type II) that shows morphological and physiological differences from type I males (Modesto \& Canário, 2003). Type II males diverge in reproductive tactics and are specialised in sneaking fertilizations (Modesto \& Canário, 2003). Interestingly, in the coast of Portugal there are several populations that differ in the degree of incidence of alternative reproductive tactics (ART). While in Tagus estuary type II males are relatively rare (ca. 10\%), in Mira estuary they represent $70 \%$ of the male population (Pereira et al. 2011). This divergence makes the Lusitanian toadfish an excellent model to study the evolution of mating systems and of ARTs.

\section{Materials \& Methods}

8 Total genomic DNA was isolated from 10 individuals using NucleoSpin tissue 96 kit (Macherey-

9 Nagel) following the manufacture's protocol, except for elution volume (we used $70 \mu \mathrm{L}$ of 0 elution buffer instead of $100 \mu \mathrm{L}$ to increase DNA concentration). A total of $1 \mu \mathrm{g}$ was used for the 1 development of microsatellite libraries through 454 GS-FLX Titanium pyrosequencing of 
42 enriched DNA libraries, as described in Malausa et al. (2011). Briefly, total DNA was enriched 43 for $\mathrm{AG}, \mathrm{AC}, \mathrm{AAC}, \mathrm{AAG}, \mathrm{AGG}, \mathrm{ACG}, \mathrm{ACAT}$, and ATCT repeat motifs and subsequently 44 amplified. PCR products were purified, quantified, and GsFLX libraries were then constructed 45 following manufacturer's protocols (Roche Diagnostics) and sequenced on a GsFLX-PTP. The 46 bioinformatics program QDD (Meglécz et al. 2010) was used to analyse sequences. QDD treats 47 all bioinformatics steps from raw sequences until obtaining PCR primers, including removal of 48 adapters/vectors, detection of microsatellites, detection of redundancy/possible mobile element 49 association, selection of sequences with target microsatellites and primer design by using 50 BLAST, ClustalW and Primer3 programs. Finally, among 10442 sequences comprising 51 microsatellites motifs, 427 bioinformatic validated pairs of primer were retrieved.

52 For the validation step, a sub-group of 48 primers pairs was tested for amplification on 14 53 DNA samples. PCR amplifications were performed in $25 \mu \mathrm{L}$ reactions containing $20 \mathrm{ng}$ of 54 template DNA, $1 \times$ reaction buffer, 37.5 pmol $\mathrm{MgCl}_{2}, 6 \mathrm{pmol} \mathrm{dNTP}, 10 \mathrm{pmol}$ of each primer, and 55 1U Taq polymerase (FastStart - Roche Diagnostics). The PCR cycling consisted of an initial 56 denaturation at $95^{\circ} \mathrm{C}$ for $10 \mathrm{~min}$, followed by 40 cycles comprising denaturation at $95^{\circ} \mathrm{C}$ for $30 \mathrm{~s}$, 57 annealing at $55^{\circ} \mathrm{C}$ for $30 \mathrm{~s}$, and extension at $72^{\circ} \mathrm{C}$ for $1 \mathrm{~min}$ and a final extension at $72^{\circ} \mathrm{C}$ for 10 $58 \mathrm{~min}$.

Primer pairs were discarded if they failed to amplify or led to multiple fragments. From 60 the 48 tested primers pairs, 15 were validated. From these, 12 microsatellite loci were selected for polymorphism study on seven DNA samples.

62 PCR amplifications were performed with the same conditions than previously but with 63 labelled primers. Each PCR product was diluted with $\mathrm{dH}_{2} \mathrm{O}$ (1:50), mixed with Hi-Di Formamide 64 and GeneScan 500 LIZ Size Standard (Applied Biosystems). Fragments were separated using an 65 Applied Biosystems 3730XL DNA Analyser. Alleles were scored using GeneMapper v5.0 66 software (Applied Biosystems).

Finally, polymorphic markers (sequences available in Electronic Supplementary Material 68 and deposited in GenBank under the accession numbers KP250581-KP250585) were used to 69 optimize multiplexed PCR and afterwards for population genotyping following the above 70 mentioned PCR conditions. The software Multiplex Manager v1.2 was used to check for markers 71 compatibility and to avoid problems like hairpins and primer-dimers. All the laboratorial 72 procedures described above were conducted at GenoScreen-France (www.genoscreen.com). 
correction), and inbreeding coefficients $\left(\mathrm{F}_{\mathrm{IS}}\right)$ were calculated with GENEPOP on the web (http://genepop.curtin.edu.au) and based on a sample of 85 individuals from the Tagus estuary. Allele sequences are provided in Supplemental Dataset S1.

This study was approved by the scientific committee of the Portuguese Foundation for Science and Technology (FCT) which evaluated the project "Role of acoustic signals in mate choice and male-male assessment in a strongly-vocal fish, Halobatrachus didactylus" (ref. PTDC/MAR/118767/2010) and the ethical forms filled by the research team. M.C.P. Amorim and P.J. Fonseca are also credited by the "Direcção Geral de Alimentação e Veterinária" (General Directorate of Food and Veterinary) as Coordinator-researcher ( $\mathrm{C}$ category) by FELASA.

\section{Results and Discussion}

The average number of alleles per locus was of 2.6 (Table 1). GENEPOP results showed that there was no heterozygote deficiency (p-values between 0.23 and 1.00) and no significant deviation from Hardy-Weinberg equilibrium was found $\left(\mathrm{X}^{2}=2.95, \mathrm{df}=10, \mathrm{p}=0.98\right.$; Fisher's method). The average observed heterozygosity over all loci (Ho) and the level of expected heterozygosity $(\mathrm{He})$ were 0.325 and 0.317 , respectively (Table 1 ). We also tested for the presence of linkage disequilibrium (LD) between pairs of loci using GENEPOP but no evidence for LD was detected ( $\mathrm{p}$-values ranged from 0.18 to 1.00 , mean=0.62).

Only five of the 12 tested loci were considered polymorphic for this population (polymorphism rate of $41.7 \%$ ), which is in agreement with the extremely low levels of genetic diversity obtained for this species by other authors (e.g. Marques et al., 2006; Robalo et al., 2013). The fact that our study was focused on a single population of the target species might have also contributed for the low number of polymorphic loci. Nevertheless, the five polymorphic loci were sufficient to address the paternity of eggs (Amorim et al., unpublished data) and so to estimate the impact of sneaking in this population. Moreover, it seems that testing more loci does not necessarily imply a higher detection of polymorphic loci.

To compare the present results with the ones of other studies, we did a brief search using as keywords "454 sequencing", "microsatellite development", "fish" and "polymorphic".We then compiled for the first 15 papers retrieved, the number of microsatellites detected, the number of tested microsatellites and, from those, the number of polymorphic loci detected. The results, described in Table 2 show that the number of loci tested in our study was below the average $(0 \%$ vs. 9\%) and that the ratio between the number of polymorphic loci (PL) and the number of tested loci (TL) was lower in our study (42\%) than the mean for the considered studies (59\%). 
107 However, a higher number of tested loci did not necessarily imply a higher polymorphism 108 detection (as depicted by the marked (**) PL/TL ratios in Table 2). In addition, although we have

109 detected a low number of polymorphic loci, Neff et al. (2000) points out that efforts should only 110 concentrate on increasing the number of loci when the male probable paternity is low. In the 111 studied population the probability of paternity by the nest-holder is high since a preliminary study 112 using these five polymorphic loci shows that nest-holders sire a high percentage of the eggs 113 found in their nests (Amorim et al., unpublished data). These microsatellite markers will allows 114 us to estimate the proportion of eggs sired by the nest-holder and by other males, the number of 115 contributing females to the batch of eggs defended by nest-holders, and the existence of filial 116 cannibalism. They will also contribute to assess fitness of different ART in Lusitanian toadfish 117 populations with contrasting incidence of type II males.

\section{REFERENCES}

119 Amorim MCP, Simões JM, Fonseca PJ, Almada VC. 2010. Patterns of shelter usage and social 120 aggregation by the vocal Lusitanian toadfish. Marine Biology 157:495-503.

121 An C-M, An HS, Lee JW, Hong SW. 2013. New polymorphic microsatellite loci for threadsail 122 filefish, Stephanolepis cirrhifer (Teleostei, Monacanthidae), from Korean waters. Genetics and 123 Molecular Research 12:1679-1690.

124 Bauchot ML. 1987. Poissons osseux. In: Fischer W, Schneider M, Bauchot ML (eds) FAO 125 d'Identification des Espèces pour les Besoins de la Pêche. Méditerranée et Mer Noire (Zone de 126 Pêche 37). Révision 1. Vol. II - Vertébrés. FAO, Rome, pp 891-1421.

127 Cardoso SD, Gonçalves D, Robalo JI, Almada VC, Canário AVM, Oliveira RF. 2013. Efficient 128 isolation of polymorphic microsatellites from high-throughput sequence data based on number of 129 repeats. Marine Genomics 11:11-16.

130 Carvalho DC, Beheregaray LB. 2010. Rapid development of microsatellites for the endangered 131 Neotropical catfish Conorhynchus conirostris using a modest amount of 454 shot-gun 132 pyrosequencing. Conservation Genetics Resources 3:373-375.

133 Carvalho DC, Hammer MP, Beheregaray LB. 2011. Isolation and PCR multiplex genotyping of 13418 novel microsatellite markers for the threatened southern pygmy perch (Nannoperca australis). 135 Conservation Genetics Resources 4:15-17. 
136 Costa JL, Almeida PR, Costa MJ. 2003. A morphometric and meristic investigation of Lusitanian

137 toadfish Halobatrachus didactylus (Bloch \& Schneider, 1801): evidence of population 138 fragmentation on Portuguese coast. Scientia Marina 67:219-231.

139 Dubut V, Grenier R, Meglécz E, Chappaz R, Costedoat C, Danancher D, Descloux S, Malausa T, 140 Martin J-F, Pech N, Gilles A. 2010. Development of 55 novel polymorphic microsatellite loci for 141 the critically endangered Zingel asper L. (Actinopterygii: Perciformes: Percidae) and cross142 species amplification in five other percids. European Journal of Wildlife Research 56:931-938.

143 Fauvelot C, Borsa P. 2011. Patterns of genetic isolation in narrow-barred Spanish mackerel 144 (Scomberomorus commerson) across the Indo-West Pacific. Biological Journal of the Linnean 145 Society 104:886-902.

146 Gardner MG, Fitch AJ, Bertozzi T, Lowe AJ. 2011. Rise of the machines - recommendations for 147 ecologists when using next generation sequencing for microsatellite development. Molecular 148 Ecology Resources 11:1093-1101.

149 Jones AG, Small CM, Paczol KA, Ratterman NL. 2010. A practical guide to methods of 150 parentage analysis. Molecular Ecology Resources 10:6-30.

151 Kang J-H, Park J-Y, Jo H-S. 2012. Rapid development of microsatellite markers with 454 152 pyrosequencing in a vulnerable fish, the mottled skate, Raja pulchra. International Journal of 153 Molecular Sciences 13:7199-7211.

154 Lü Z, Li H, Liu L, Cui W, Hu X, Wang C. 2013. Rapid development of microsatelitte markers 155 from the large yellow croaker (Pseudosciaena crocea) using next generation DNA sequencing 156 technology. Biochemical Systematics and Ecology 51:314-319.

157 Malausa T, Gilles A, Meglécz E, Blanquart H, Duthoy S, Costedoat C, Dubut V, Pech N, 158 Castagnone-Sereno P, Délye C, Feau N, Frey P, Gauthier P, Guillemaud T, Hazard L, Le Corre V, 159 Lung-Escarmant B, Malé PJ, Ferreira S, Martin JF. 2011. High-throughput microsatellite 160 isolation through 454 GS-FLX Titanium pyrosequencing of enriched DNA libraries. Molecular 161 Ecology Resources 11:638-644.

162 Marques JF, Rego AL, Costa JL, Costa MJ, Cabral H. 2006. Genetic and morphological 163 differentiation of the Lusitanian roadfish (Halobatrachus didactylus) between estuarine and 164 coastal areas in Portugal. Scientia Marina 70:749-758.

165 Meglécz E, Costedoat C, Dubut V, Gilles A, Malausa T, Pech N, Martin JF. 2010. QDD: A user166 friendly program to select microsatellite markers and design primers from large sequencing 167 projects. Bioinformatics 26:403-404. 
168 Modesto T, Canário AVM. 2003. Morphometric changes and sex steroid levels during the annual 169 reproductive cycle of the Lusitanian toadfish, Halobatrachus didactylus. General and 170 Comparative Endocrinology 131:220-231.

171 Muths D, Bourjea J. 2011. Isolation and characterization of thirteen polymorphic microsatellite

172 markers from the bluestriped snappers Lutjanus kasmira and L. bengalensis. Molecular Ecology 173 Resources 11:935-936.

174 Neff BD, Repka J, Gross MR. 2000. Statistical confidence in parentage analysis with incomplete 175 sampling: how many loci and offspring are needed? Molecular Ecology 9:529-539.

176 Pereira TJ, Silva G, Costa MJ, Costa JL. 2011. Life strategies of Halobatrachus didactylus 177 (Bloch and Schneider, 1801) in the Tagus estuary: comparison among morphotypes. Estuarine, 178 Coastal and Shelf Science 93:328-335.

179 Quintela M, Danielsen EA, Svasand T, Knutsen H, Skiftesvik AB, Glover KA. 2014. Isolation 180 and characterization of twenty microsatellite loci for the ballan wrasse, Labrus bergylta. 181 Conservation Genetics Resources 6:425-428.

182 Robalo JI, Crespo AM, Castilho R, Francisco SM, Amorim MCP, Almada VC. 2013. Are local 183 extinctions and recolonizations continuing at the colder limits of marine 184 fish distributions? Halobatrachus didactylus (Bloch \& Schneider, 1801) a possible candidate. 185 Marine Biology 160:2461-2467.

186 Roux C. 1986. Batrachoididae. In: Whitehead PJP, Bauchot ML, Hureau JC, Nielsen J, Tortonese 187 E (eds) Fishes of the North-eastern Atlantic and Mediterranean, vol.III, UNESCO, Paris, pp 188 1360-1361.

189 Tautz D. 1989. Hypervariability of simple sequences as a general source for polymorphic DNA 190 markers. Nucleic Acids Research 17:6463-6471.

191 Teixeira S, Candeias R, Klein M, Serrão EA, Borges R. 2013. Characterization of 15 192 polymorphic microsatellite loci in the temperate reef fish Lepadogaster lepadogaster, developed 193 using 454-sequencing. Conservation Genetics Resources 5:55-57.

194 Umbers KDL, Jennions MD, Gardner MG, Keogh JS. 2012. Twenty-five new polymorphic 195 microsatellites for the eastern mosquitofish, Gambusia holbrooki (Actionopterygii: Poecillidae), 196 an invasive species in Australia. Australian Journal of Zoology 60:235-237.

197 Vasconcelos RO, Carriço R, Ramos A, Modesto T, Fonseca PJ, Amorim MCP. 2012. Vocal 198 behavior predicts reproductive success in a teleost fish. Behavioral Ecology 23:375-383. Wang J, 199 Yu X, Zhao K, Zhang Y, Tong J, Peng Z. 2012. Microsatellite development for an endangered 
200 bream Megalobrama pellegrini (Teleostei, Cyprinidae) using 454 sequencing. International 201 Journal of Molecular Sciences 13:3009-3021.

202 Zeng Q, Ye H, Ludwig A, Wang Z, Peng Z. 2013. Microsatellite development for the endangered 203 Yangtze sturgeon (Acipenser dabryanus Duméril, 1869) using 454 sequencing. Journal of 204 Applied Ichthyology 29:1219-1221. 


\section{Table 1 (on next page)}

Table 1

Characterization of 5 polymorphic microsatellite loci for $H$. didactylus. 
1Table 1 - Characterization of 5 polymorphic microsatellite loci for $H$. didactylus.

\begin{tabular}{|c|c|c|c|c|c|c|c|c|c|c|}
\hline Marker & Forward Primer sequence $\left(5^{\prime}-3^{\prime}\right)$ & Reverse Primer sequence (5'-3') & $\begin{array}{c}\text { Fluorescent } \\
\text { dye }\end{array}$ & $\begin{array}{c}\text { Repeat } \\
\text { motif }\end{array}$ & $\begin{array}{l}\text { Expected } \\
\text { size (bp) }\end{array}$ & $\begin{array}{c}\text { Size } \\
\text { range } \\
\text { (bp) }\end{array}$ & $\mathrm{N}_{\mathrm{a}}$ & $\mathrm{H}_{\mathrm{e}}$ & $\mathrm{H}_{\mathrm{o}}$ & $\mathrm{F}_{\text {IS }}$ \\
\hline Loc11 & TCACCTGTGAGAGCGAGAAA & TGCACCTGATCCTAAATCCA & VIC & $(\mathrm{GA})_{16}$ & 135 & $121-135$ & 2 & 0.101 & 0.106 & -0.050 \\
\hline Loc16 & ACTCGAACCACAATTCTGCC & CGAACAGGGAAGGAAATCAC & NED & $(\mathrm{AC})_{18}$ & 110 & $107-114$ & 4 & 0.628 & 0.600 & 0.045 \\
\hline Loc26 & ATGTCTCTTTGTACATTTGTATCTCTG & AAAACTACCAACTGGTCCTCACA & 6FAM & $(\mathrm{TG})_{11}$ & 148 & $157-159$ & 2 & 0.322 & 0.353 & -0.097 \\
\hline Loc27 & AACATCAGAACATCTGTCAATTCAA & GTCTGGTGCACATGGTGAGT & VIC & $(\mathrm{AC})_{12}$ & 290 & $295-297$ & 2 & 0.079 & 0.082 & -0.038 \\
\hline Loc36 & GAAAGGGTCACCATGACAGG & TGCCAACAGTGAAGCAGTTT & PET & $(\mathrm{AC})_{14}$ & 139 & $145-167$ & 3 & 0.452 & 0.482 & -0.067 \\
\hline
\end{tabular}

2Size range of fragments (bp), number of alleles $(\mathrm{Na})$, expected $\left(\mathrm{H}_{\mathrm{e}}\right)$ and observed $\left(\mathrm{H}_{\mathrm{o}}\right)$ heterozygosity, and inbreeding coefficient $\left(\mathrm{F}_{\mathrm{IS}}\right)$, based on a sample of 85

3individuals. 


\section{Table 2 (on next page)}

Table 2

Overview of a brief search on polymorphic microsatellites developed by 454 sequencing for fish species: number of identified, tested and polymorphic loci and their comparison with the values obtain for the present study. ** studies for which the PL/TL ratio was lower than that obtained in the present study. 
1 Table 2 - Overview of a brief search on polymorphic microsatellites developed by 454 sequencing for fish species: number of identified, tested and polymorphic 2 loci and their comparison with the values obtain for the present study. ** studies for which the PL/TL ratio was lower than that obtained in the present study.

\begin{tabular}{|c|c|c|c|c|c|c|}
\hline Authors & Target species & $\begin{array}{c}\text { identified } \\
\text { loci (IL) }\end{array}$ & $\begin{array}{c}\text { tested loci } \\
(\mathrm{TL})\end{array}$ & $\begin{array}{c}\text { polymorphic } \\
\text { loci }(\mathrm{PL})\end{array}$ & TL/IL & $\mathrm{PL} / \mathrm{TL}$ \\
\hline & Halobatrachus didactylus & 10442 & 12 & 5 & $0 \%$ & $42 \%$ \\
\hline Cardoso et al. 2013 & Salaria pavo & 4190 & 28 & 26 & $1 \%$ & $93 \%$ \\
\hline Carvalho \& Beheregaray 2010 & Conorhynchus conirostris & 3796 & 20 & 13 & $1 \%$ & $65 \%$ \\
\hline Quintela et al. 2014 & Labrus bergylta & 92 & 43 & 22 & $47 \%$ & $51 \%$ \\
\hline Kang et al. 2012 & Raja pulchra & 17033 & 20 & 14 & $0 \%$ & $70 \%$ \\
\hline Wang et al. 2012 & Megalobrama pellegrini & 24522 & 33 & 26 & $0 \%$ & $79 \%$ \\
\hline An et al. 2013 & Stephanolepis cirrhifer & 5350 & 74 & 24 & $1 \%$ & $32 \% * *$ \\
\hline Zeng et al. 2013 & Acipenser dabryanus & 17609 & 80 & 8 & $0 \%$ & $10 \% * *$ \\
\hline Carvalho et al. 2011 & Nannoperca obscura & 9476 & 21 & 15 & $0 \%$ & $71 \%$ \\
\hline Umbers et al. 2012 & Gambusia holbrooki & 1187 & 40 & 25 & $3 \%$ & $63 \%$ \\
\hline Muths \& Bourjea 2011 & Lutjanus kasmira & 3022 & 16 & 13 & $1 \%$ & $81 \%$ \\
\hline Dubut et al. 2010 & Zingel asper & 241 & 105 & 55 & $44 \%$ & $52 \%$ \\
\hline Dubut et al. 2010 & Sander lucioperca & 241 & 47 & 18 & $20 \%$ & $38 \% * *$ \\
\hline Dubut et al. 2010 & Perca fluviatilis & 241 & 35 & 14 & $15 \%$ & $40 \% * *$ \\
\hline Lu et al. 2013 & Pseudosciaena crocea & 2535 & 32 & 27 & $1 \%$ & $84 \%$ \\
\hline \multirow[t]{2}{*}{ Teixeira et al. 2013} & Lepadogaster lepadogaster & 10258 & 25 & 15 & $0 \%$ & $60 \%$ \\
\hline & MEAN VALUES & 6214.2 & 41.3 & 21.0 & $9 \%$ & $59 \%$ \\
\hline
\end{tabular}

